\title{
Mosaico de trás para frente
}

\author{
Backwards mosaic \\ Mosaico de atrás para adelante
}

Rodrigo Bentes Monteiro*

Gesteira, Heloisa Meireles; Leal, João Eurípedes Franklin; Santiago, Maria Claudia (orgs.). Formulário médico. Manuscrito atribuido aos jesuitas e encontrado em uma arca da igreja de São Francisco de Curitiba. Rio de Janeiro: Editora Fiocruz, 2019. 434 p.

A interpretação e a materialidade de manuscritos da Época Moderna, conforme a preposição "da" atrás empregada, procura ressaltar que os manuscritos a serem analisados são provenientes do período situado, grosso modo, entre os séculos XVI e XVIII. Náo raro esses textos chegam ao presente experimentando autorias diversas, além de intervençóes de copistas, proprietários, restauradores e leitores. Portanto, os manuscritos não deveriam ser percebidos hoje como se estivessem simplesmente "na" Época Moderna - eis aí a sutil diferença. A perspectiva vincula-se ao tema da materialidade social, uma apropriação do trabalho de Donald McKenzie sobre a bibliografia entendida como sociologia dos textos (MCKENZIE, 2018). Os textos, enquanto tecidos com textura (conforme a origem latina das palavras), sejam manuscritos ou impressos, possuem uma materialidade a ser estudada. Mas sua matéria é também social e histórica, a ser considerada na análise de um artefato proveniente de outro tempo, que passa por metamorfoses até chegar ao momento atual. Decorre daí a importância de se abordar nas pesquisas o percurso dos documentos - manuscritos ou impressos - em meio a arquivos particulares ou públicos. É fundamental também lidar com as diferentes leituras, por vezes expressas no próprio corpus documental, do objeto, mediante comentários, anotaçôes nas margens etc., ou quando os manuscritos são transcritos, editados e impressos em forma parcial ou integral e passam a ser comentados por leitores vários,

DOI: http://dx.doi.org/10.1590/2237-101X02204714

Resenha recebida em 19 de novembro de 2019 e aceita para publicação em 7 de abril de 2020.

* Professor da Universidade Federal Fluminense, Instituto de História, Rio de Janeiro/ RJ - Brasil. Bolsista de Produtividade CNPq 2. E-mail: rnbentesmonteiro@id.uff.br. ORCID: https://orcid.org/0000-0002-6499-9912. 
assumindo divulgação mais ampla por meio de publicaçôes.

A percepção do anacronismo inerente ao ofício do historiador relaciona-se com a consciência de que o texto e sua matéria provêm de outro tempo. Evita-se assim a suposição ingênua de que a leitura de um manuscrito abre per se uma janela para o passado, desde que se dê atençáo a formas textuais e ideias nele expressas - no caso de um receituário médico do século XVII ou XVIII - ou querendo livrar o códice das interferências indesejáveis por ele sofridas, como carimbos, notas, restauraçóes tidas à conta de equivocadas etc.

Diferentemente, nesta publicação há a perspectiva de que o documento histórico, manuscrito ou impresso, carrega consigo as transformaçôes vividas tanto em termos materiais como abstratos, pois as leituras e comentários feitos sobre um texto através dos tempos também influenciam, mesmo de forma inconsciente, a nossa percepção atual. No decorrer das décadas frequentemente reproduzimos opiniōes sobre um documento proveniente da Época Moderna sem muita crítica, sem indagar se os antecessores examinaram acuradamente seu texto e não apenas partes desse, se os processos de edição e impressáo do manuscrito foram criteriosos, ou se os estudiosos de outrora eram condicionados por convicçóes estabelecidas a priori.

Conforme trabalhos de Umberto Eco, adquirimos a lucidez do inevitável anacronismo subjacente a essa operaçáo cognitiva (ECO, 2010; ECO, 2011), por exemplo ao tentar favorecer a interpretação de um manuscrito (cujo texto agora possui a sua versão impressa) e ao possibilitar a análise documental distinta da leitura parcial e intermediada por fatores vários. Assim se consideram as leituras feitas e as intervençôes materiais sofridas - do tempo, do ambiente, de pessoas - como um processo normal. Essa perspectiva enriquece a investigaçáo histórica, ao romper por um lado com as balizas temporais, e por outro fazer lidar com as especificidades de todas as épocas e contextos, desde as circunstâncias de produção do manuscrito, passando por suas primeiras recepçóes até o tempo das apropriações e talvez publicaçôes.

Entretanto, leituras parciais frequentemente tomam a parte pelo todo em relaçáo ao documento, ao contemplarem somente extratos seus, ou são por demais ideológicas, ao informarem mais acerca do leitor que do sentido primeiro de produção daquele objeto em análise. Leituras assim não historicizam bem o texto e sua materialidade. São diferentes das interpretaçôes, que almejam uma compreensão integral do documento, procurando captar as circunstâncias de sua produção e o conjunto de suas características.

Para se construir interpretaçóes mais abrangentes de manuscritos oriundos da Época Moderna, é necessário conjugar saberes, no exercício da interdisciplinaridade. Durante o século XX, devido ao incremento dos processos editoriais e a vários outros fatores, os historiadores perderam gradualmente o contato cotidiano com bibliotecários, arquivistas, paleógrafos e restauradores. Com a digitalização recente de fundos arquivísticos e bibliográficos, esse afastamento tem sido uma armadilha séria, sobretudo para estudantes de 
pós-graduação, ao fazer deixar de lado os caminhos mais lentos pelos quais os documentos vindos de outro tempo foram criados e construíram os seus percursos.

Felizmente, nos últimos anos as relações entre diferentes profissionais nos âmbitos da história do livro e da leitura, da cultura escrita e visual, vão sendo revitalizadas, por um lado com o desenvolvimento de novas tecnologias, por outro pela própria renovação do campo de estudos. No caso da história moderna, com a implosão de velhas fronteiras epistemológicas que faziam a história política correr em separado das histórias da ciência, religiosa, econômica etc. Paradoxalmente, trata-se de empregar o mais inovador em termos tecnológicos para estudar o velho, pois a informação histórica preservada é composta, em grande número, por papéis artesanais, caligrafias diversas, cadernos e substâncias variadas como as tintas metaloácidas.

É preciso também fortalecer instituições como a Casa de Oswaldo Cruz, incentivando ações de conservação de documentos e a sua pesquisa, para que manuscritos e impressos sejam preservados e acessíveis fisicamente, quando necessário, aos investigadores contemporâneos, sem excluir as cópias digitais, valiosas na leitura e na identificação de muitos aspectos. $\mathrm{O}$ trabalho apresentado a público é um grande mosaico de estudos que cumpre a função de abrir o campo para investigaçóes posteriores que lidem com o chamado Formulário médico.

A começar - e continua-se de trás para frente - pela última parte do livro, sucedida por um glossário que elucida os menos versados na matéria, complementando a uti- lidade desta edição aos estudiosos. Trata-se da transcrição paleográfica, fundamental para filólogos e estudiosos da língua, como salienta João Eurípedes Franklin Leal, mas também para os historiadores. Alguns colegas adotam a prática da atualização ortográfica para a melhor apreensão do texto de outrora, pois a história é sempre anacrônica etc. No entanto, a transcrição paleográfica de um texto longo pode ser uma importante ferramenta para se perceber as cópias eventualmente feitas de trechos de impressos ou outros manuscritos, algo ainda mais evidente ao lidarmos com um tempo no qual não havia normatização ortográfica da língua portuguesa, quando autores eram imitadores, por isso mesmo mais leitores, compiladores e copistas do que propriamente criadores textuais. Ou seja, por meio de uma transcrição atenta aos grafemas, identificam-se leituras e cópias feitas de outros textos impressos ou manuscritos. Não se trata de purismo acadêmico, mas da convicção de que a boa transcrição documental possibilita a melhor pesquisa histórica, no caso pelas mãos competentes da equipe de Franklin Leal.

Em seguida e à frente, pela grande aula acerca dos exames material e visual ministrada pelo grupo de vários especialistas, evidenciando a importância do estudo dos suportes neste capítulo. Os autores descrevem os instrumentos utilizados para definir o tipo de papel, a forma e a época de produção e organização dos cadernos, o modo como o volume foi encadernado, o recorte das folhas, as marcas d'água, a tinta utilizada e as intervençóes sofridas. Vestígios químicos encontrados também indicam o 
tempo daquela produção artesanal, mediante a comparação com outros documentos. A equipe é atenta assim às transformações sofridas pelo manuscrito ao longo do tempo, observando que os carimbos nas primeiras páginas existentes foram feitos após a perda das duas primeiras folhas originais. Ademais, as manchas d'água, os rasgos e dobras parecem sugerir a trajetória movimentada do dito Formulário, possivelmente com ampla circulação. Destaque-se ainda o respeito da equipe autoral pela restauração feita em tempo recente, preservando o manuscrito para análise, mas também resultando em perda de informaçóes.

Já o capítulo de Eliane Deckmann Fle$\mathrm{ck}$, se por um lado não lida diretamente com o manuscrito em tela, por outro contextualiza o âmbito de circulação de receituários no sul do Brasil, mediante os cadernos de missionários. Nesses manuscritos revela-se a interação entre saberes europeus e indígenas - algo presente no Formulário pelos termos empregados - e a importância dos colégios jesuíticos, com herbários, hospitais e boticas, na circulação de saberes e na prática experimental em regióes periféricas dos impérios ibéricos ultramarinos.

Diferente é o capítulo de Bruno Boto Leite, que persegue a diacronia para mostrar as origens do ofício de boticário na América portuguesa, recuando até a Europa medieval para tratar do surgimento das boticas como arte mecânica, em seguida sua valorização no século XVII, até ser ofuscado pelo desenvolvimento da química. Ao início do capítulo, Bruno Leite observa a marca de propriedade existente no Formulário, de
Oliveira Catramby, personagem do Brasil no século XIX, sinalizando a necessidade de estudos que investiguem essa guarda particular, bem como a atribuição aos jesuítas feita justamente por este bibliófilo ou parente seu. Ao fim, conjectura se a autoria deste caderno de receitas provém de um possível boticário leigo, Manoel de Oliveira Cerial, sendo atribuído aos jesuítas em momento posterior. Contudo, se Cerial descreve-se no Formulário (na primeira pessoa) como autor de uma receita, na cultura compilatória que caracteriza a confecção de manuscritos vindos da Época Moderna pode ser ousado tomar a parte pelo todo.

$\mathrm{O}$ caso faz pensar nos cancioneiros quinhentistas existentes em Portugal, com muitos poemas atribuídos a Camóes sem de fato o serem - assunto de infindáveis controvérsias entre filólogos e críticos (SENA, 1980, p. 135-170). Também nos cadernos contendo poemas da Bahia seiscentista, no século XVIII sendo atribuídos a Gregório de Matos, conforme os estudos de João Adolfo Hansen e Marcello Moreira (HANSEN, 2004; MOREIRA, 2011). Uma questão complexa, e há que se distinguir entre autoria gráfica e intelectual. $\mathrm{O}$ fato do manuscrito ter sido feito sem rasuras ou correçóes sugere que o único autor gráfico (conforme a equipe de paleógrafos identifica a caligrafia) copiou as receitas. Mas este não seria necessariamente o autor intelectual, ou mesmo um dos autores intelectuais das receitas - algo plausível, dado o perfil compilatório e colaborativo daqueles textos (LOVE, 2002).

Por fim e ao início, Heloisa Meireles Gesteira costura conteúdos expostos no li- 
vro, apontando para a importância da circulação de ideias e experiências mais ou menos relacionadas à Companhia de Jesus, interagindo com grupos indígenas e produtos vindos das quatro partes do mundo. Pelo exame do texto, Meireles Gesteira busca pistas sobre os passos e os espaços de sua elaboração (os índios do Cariri, as referências ao planalto paulista), entendendo o documento como uma fonte expressiva da sistematização de saberes médicos à época. Trata-se então de um grande caderno provavelmente utilizado em boticas e enfermarias, que pode ter sido fruto de experiências várias e circulado por diferentes lugares e agentes, conforme o trabalho seminal de Fernando Bouza, centrado na Espanha do Século do Ouro (BOUZA, 2001), ou a maior proximidade temática do estudo de Kapil Raj (RAJ, 2010). Seguindo a ênfase do manuscrito, Gesteira concede mais atenção às plantas presentes nas receitas que aos animais e minerais e - como Bruno Boto Leite - observa a simbiose existente entre práticas mágicas e médicas, na esteira dos trabalhos de Márcia Moisés Ribeiro e outros, sem oposição entre o erudito e o popular (RIBEIRO, 1997; CALAINHO, 2005). A análise intertextual entre alguns cadernos manuscritos e livros impressos, consoante à cultura compilatória referida e à boa transcrição feita, a meu ver deveria prosseguir, possivelmente conduzindo a avanços na datação do Formulário.

Portanto, trata-se de um mosaico de estudos sem conclusóes fechadas ou necessariamente concordantes entre si, nos quais se destaca a cautela dos estudiosos em não proferir julgamentos taxativos sobre as cir- cunstâncias de produção do manuscrito. Expressôes como "possivelmente", "conjectura-se", "por outro lado", são frequentes nos capítulos, mais do que as assertivas, sendo um sinal da competência do grupo dedicado. Conquanto não haja uma interpretação cabal do códice em tela, sua complexidade é um incentivo para trabalhos posteriores que venham a valer-se desta publicação. Um trabalho interdisciplinar que conjuga saberes de ordem paleográfica, histórica e material para apreender o mundo plural do qual provém o manuscrito, protagonista do livro ora impresso. O livro aborda temas relevantes aos interessados, como a produção gráfica e a confecção de manuscritos, a organização da informação, a questão da autoria, as trajetórias dos documentos e sua circulação. Estimula assim novas pesquisas sobre este texto e outros a ele correlatos, não apenas pelos conteúdos específicos que veicula na área de história da ciência e das práticas médicas, mas pelo que comunica e instrui em termos epistemológicos e metodológicos. Incentiva, ainda, a boa política pública na gestão de documentos por parte da Fundação Oswaldo Cruz, por meio da organização de Maria Claudia Santiago, bibliotecária da seção de obras raras da Biblioteca de Manguinhos, lembrando o recente estatuto adquirido pelo manuscrito junto à Unesco.

Referências

BOUZA, Fernando. Corre manuscrito. Una historia cultural del Siglo de Oro. Madri: Marcial Pons, 2001. 
CALAINHO, Daniela Buono. Jesuítas e introduction. Cambridge: Cambridge medicina no Brasil colonial. Tempo, Niterói, University Press, 2002.

v. 10, n. 19, p. 61-75, jul./dez. 2005. MCKENZIE, Donald. F. [1999]. ECO, Umberto [1999]. As formas do Bibliografia e a sociologia dos textos. Tradução conteúdo. Tradução de Pérola de Carvalho. de Fernanda Veríssimo. São Paulo: Edusp, São Paulo: Perspectiva, 2010. 2018.

ECO, Umberto [1979]. Lector in fabula. $A$ cooperação interpretativa nos textos narrativos. Tradução de Attílio Cancian. São Paulo: Perspectiva, 2011.

MOREIRA, Marcello. Critica textualis in caelum revocata? Uma proposta de edição e estudo da tradição de Gregório de Matos e Guerra. Sáo Paulo: Edusp, 2011.

GESTEIRA, Heloisa Meireles; LEAL, João Eurípedes Franklin; SANTIAGO, Maria Claudia (orgs.). Formulário médico. Manuscrito atribuido aos jesuitas e encontrado em uma arca da igreja de São Francisco de Curitiba. Rio de Janeiro: Editora Fiocruz, 2019.

HANSEN, João Adolfo [1989]. A sátira e o engenho. Gregório de Matos e a Babia no século XVII. São Paulo/Campinas: Ateliê Editorial/Editora Unicamp, 2004.

RAJ, Kapil. Relocating Modern Science: circulation and the construction of knowledge in South Asia and Europe, 16501900. Basingstoke: Palgrave Macmillan, 2010.

RIBEIRO, Márcia Moisés. A ciência dos trópicos. A arte médica no Brasil do século XVIII. São Paulo: Hucitec, 1997.

SENA, Jorge de. Trinta anos de Camóes 1948-1978 (estudos camonianos e correlatos). Lisboa: Ediçôes 70, 1980.

LOVE, Harold. Attributing autorship: an 